Article

\title{
Brief Accuracy Assessment of Aerosol Climatologies for the Retrieval of Solar Surface Radiation
}

\section{Richard Mueller * and Christine Träger-Chatterjee}

Department of Climate and Environment, Deutscher Wetterdienst, Frankfurter Str. 135, 60385

Offenbach, Germany; E-Mail: Christine.Traeger-Chatterjee@dwd.de

* Author to whom correspondence should be addressed; E-Mail: Richard.Mueller@dwd.de; Tel.: +49-8062-4922.

External Editor: Evgueni Kassianov

Received: 8 August 2014; in revised form: 5 November 2014 / Accepted: 12 November 2014 / Published: 3 December 2014

\begin{abstract}
Solar surface irradiance is an important variable in many different fields, e.g., climate monitoring and solar energy. Remote sensing data are nowadays well established and the only observational data source in many regions of the world. Aerosols significantly affect the clear sky radiation and hence also the all sky radiation. In order to achieve the optimal accuracy for surface radiation, information of aerosols with low uncertainty is needed. In this study, the effect of four different aerosol climatologies on the solar surface radiation have been evaluated for the period 2006-2009 at nine BSRN stations. The use of the aerosol climatology from the European Center of Medium Weather Forecast (MACC) leads to the highest accuracy of solar radiation. The mean absolute bias is 6.8 Watt per square meter for global irradiance and 11.3 for direct irradiance. With the Max-Planck climatology (MAC-v1) 9.4 and 14.8 Watt per square meter and with GADS/OPAC (Global Aerosol Data Set/Optical Properties of Aerosols and Clouds) 10.0 and 14.6 Watt per square meter have been achieved, respectively. The improvement in the accuracy of solar radiation by using the MACC climatology is relatively large. Also remarkable is that the new MAC-v1 climatology and the older GADS/OPAC climatology performs on the same level with respect to the achieved accuracy in radiation. The effect of interannual variations of Aerosol Optical Depth (AOD) on the global irradiance is rather low for the investigated sites and period.
\end{abstract}

Keywords: aerosol climatology; global irradiance; direct irradiance 


\section{Introduction}

Solar surface irradiance is an essential climate variable needed for the monitoring of the Earth's radiation budget and the analysis of the solar radiation feedback of the atmosphere. Further, it is of importance for the satellite based estimation of drought and evaporation and hence the analysis of the hydrological cycle, e.g., [1] and references therein. Moreover, these data are useful for the verification of reanalysis data, e.g., [2,3]. Furthermore, accurate solar surface irradiance data are essential for the planning and monitoring of solar energy systems [4].

Solar surface irradiance assessment from geostationary satellites is the primary source of observational data in regions where ground based measurements are rare (e.g., over ocean and on the African continent). Moreover it is useful to supplement ground measurements in regions with a dense coverage of measurement stations (e.g., [5]).

Various algorithms have been developed to produce surface solar radiation data sets (e. g., [6-12]) covering different approaches. All of them need aerosol or turbidity information as input. Aerosols have a significant effect on the solar surface irradiance. In order to achieve the optimal accuracy for surface radiation, information on aerosols with low uncertainty is needed, particularly in regions with low cloud frequency.

Unfortunately, the uncertainty of remote sensing aerosol information is relatively high over land [13] and the network of ground measurements is rather sparse e.g., [14]. These might be the reasons why in many applications climatologies of aerosols or turbidity are used instead of monthly resolved time series. To the knowledge of the authors this is the case for the retrievals applied by the Satellite Application Facilities (SAF) on Land Surface Analysis (LSA SAF) [15], Ocean and Sea Ice (OCI SAF), Climate Monitoring (CM SAF) [16], as well as within Satellight [17], Solar Radiation Data (SODA) [18] and PVGIS [19], to mention some examples. Further, for climate monitoring stability and homogeneity are essential. However, since the time coverage of aerosol datasets is an issue, the production of long term solar irradiance datasets using monthly resolved long term aerosol data would require a mixing of data sources. This in turn is expected to induce inhomogeneities (see Figure 1). The use of climatologies, on the other hand, provides a consistent treatment of aerosols throughout the time series and avoids the need for mixing of data sources.

This and the prevailing use of climatologies within remote sensing of solar surface radiation motivates the investigation of the accuracy of solar surface radiation for different aerosol climatologies. In this study the effect of four different aerosol data on the retrieval of solar surface irradiance are investigated. The goal is to determine the aerosol data base which provides the solar surface irradiance with the highest accuracy for the investigated sites. Also the inter-annual variability of the different aerosol databases is briefly discussed.

For this study the solar surface irradiance retrieval of the Satellite Application Facility on Climate Monitoring [20] is applied. The method is based on a Heliosat approach for the calculation of the cloud transmission [4,7,21] and is described in detail in [21,22]. A short outline of the Heliosat approach in given below:

The cloud transmission is derived from the effective cloud albedo by

$$
G / G_{\text {clear }}=1-C A L
$$


Figure 1. Illustration of the difference in surface radiation (Air Mass $=2$ ), here direct normal irradiance for March, induced by the use of different aerosol climatologies (Kinne versus Global Aerosol Data Set/Optical Properties of Aerosols and Clouds (GADS/OPAC), see Section 2 for further details about the climatologies). The large differences in Direct Normal Irradiance (DNI) illustrates that the mix of different data sources is expected to lead to serious inhomogeneities in climate data records.

d DNI (Watt per square meter), March

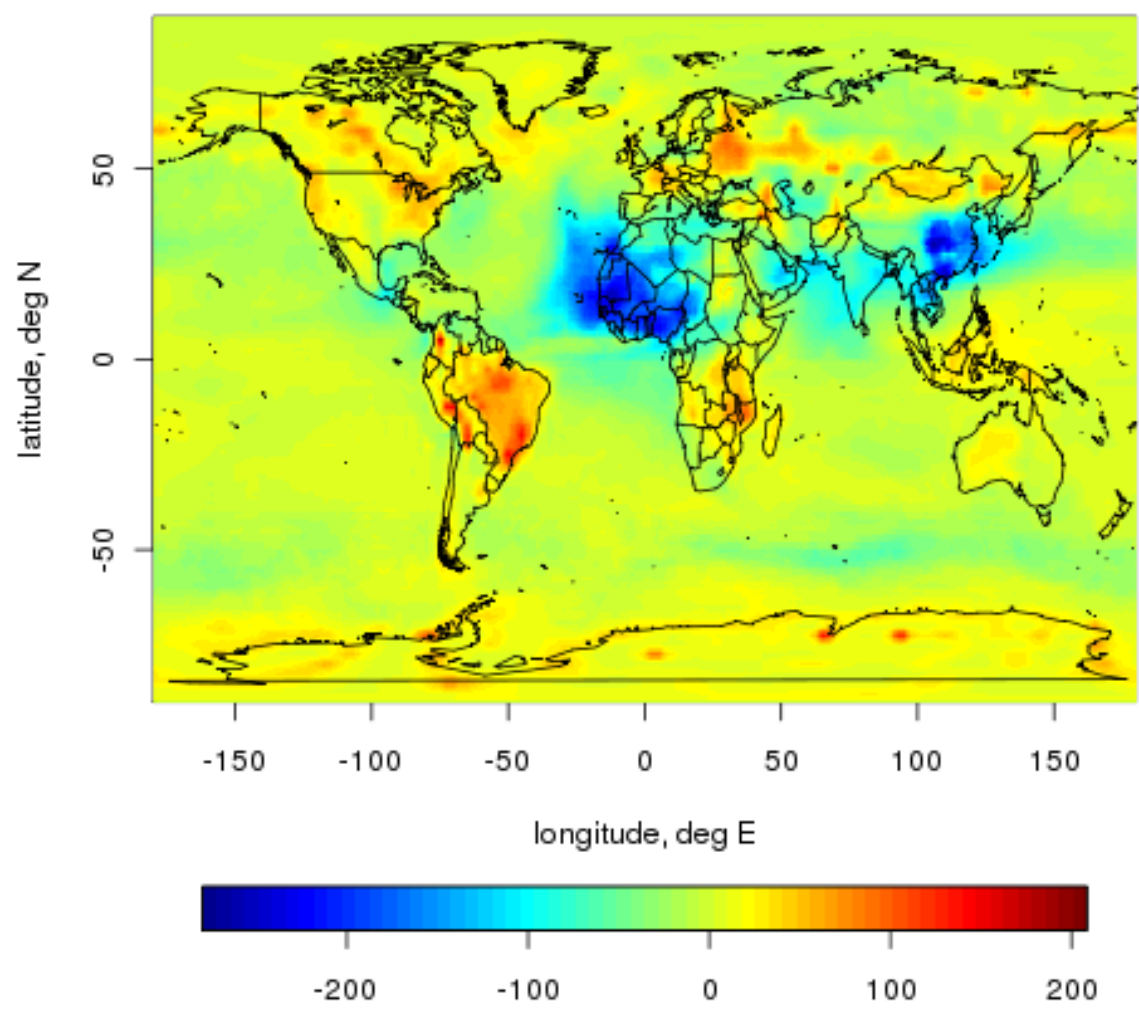

The effective cloud albedo (CAL) in turn is derived from the normalised reflections observed by the satellite by Equation (2):

$$
C A L=\frac{\rho-\rho_{c s}}{\rho_{\max }-\rho_{c s}}
$$

here, $\rho$ is the normalised observed reflection for each pixel and time, $\rho_{c s}$ is the minimum reflection per slot, pixel and month and $\rho_{\max }$ is the "maximum" reflection. The latter is determined by the 95th percentile of all reflection values at local noon in a target region characterised by a high frequency of cloud occurrence for each month.

The all sky irradiance $G$ is then derived by applying the clear sky model $\left(G_{\text {clear }}\right)$ [22] and Equation (1). The applied clear sky model consists of look-up tables calculated with the radiative transfer model libradtran [23] for the consideration of aerosols. Further, it includes parameterisations of water vapour and ozone, which are validated with libradtran. The spectral effect of aerosols is considered by application of a standard aerosol model [24,25].

The resulting all sky method SPECMAGIC [22] and its precursor MAGICSOL [26] are well established and enable the consideration of clouds, water vapour, aerosol optical depth and aerosol type. Similar methods are used by many other groups as well, e.g., the Land Surface Analysis SAF, the Ocean 
and Sea Ice SAF, Universtiy of Oldenburg, and Armines, please see [4,11,16] as well as [12,21,22,27] and references therein for further details. The outlined Heliosat approach [4,7,11], and its coupling with clear sky models is a standard method for the retrieval of solar irradiance from Meteosat First Generation satellites. It is therefore expected that the evaluation results are of general interest for the solar radiation community.

\section{The Investigated Aerosol Data Sets}

All data sets have a global coverage and long term monthly means ("climatological monthly means") are used for the comparison study.

The "Kinne" climatology The first aerosol climatology investigated is referred as Kinne climatology. It has been generated within a work contract for the DWD. For information about the aerosol state an aerosol climatology based on AEROCOM data [13] merged with ground based measurements from the AErosol RObotic NETwork (AERONET) [28] is used. It comes as a climatology of monthly means in $1 \times 1$ degree resolution. The merging has been performed by the application of inverse distance weighting of the ground measurements. This climatology has been used for the generation of the first CM SAF (Climate Monitoring Satellite Application Facility) radiation climate data record [26].

The MAC-v1 climatology As a second data base the Max-Planck-Institute Aerosol Climatology version 1 (MAC-v1) aerosol climatology is tested [29]. Again the Aerocom global modeling inter-comparison is the starting point of the data set. Midvisible $(550 \mathrm{~nm})$ averages of Aerosol Optical Depth (AOD) and Single Scattering Albedo (SSA) and fine-mode AOD fraction are obtained from statistical merging of ground based sun- and sky-photometer with data from AeroCom phase1 global modeling. In comparison to the afore mentioned method, the data mining and merging is more complex and readers are referred to [29] for further details about the method and further information about the available aerosol properties. The monthly means with a spatial resolution of $1 \times 1$ degree are publicly available at [30].

The GADS/OPAC climatology A further aerosol climatology evaluated results from the calculation of optical properties with the Optical Properties of Aerosols and Clouds (OPAC) software package using the Global Aerosol Data Set (GADS) as input [31]. GADS provides information on the atmospheric aerosol particles for 10 main aerosol components which are representative for the atmosphere and characterised through their size distribution and their refractive index. This information is provided on a $5 \times 5$ degree grid for summer and winter time. The optical properties are calculated with OPAC by consideration of the relative humidity taken from the National Center for Environmental Prediction (NCEP) [32]. OPAC is able to consider the effect of aerosol swelling and hence the effect of relative humidity on aerosol optical depth, single scattering albedo and asymmetry parameter. By consideration of relative humidity data long term monthly means on $2.5 \times 2.5$ degree are generated and used.

The MACC climatology Finally, the MACC reanalysis product is used [33]. The MACC product is obtained from a data assimilation system for global reactive gases, aerosols, and greenhouse gases. 
It consists of a forward model for aerosol composition and dynamics [34]. The data assimilation procedure is described in detail in [35]. It has recently been used for the estimation of aerosol radiative forcing [36]. The MACC reanalysis product is generated with a T159 horizontal resolution. For the use in SPECMAGIC it has been re-gridded to a $0.5 \times 0.5$ degree regular latitude longitude grid.

The required aerosol optical properties (at $550 \mathrm{~nm}$ wavelength) are: aerosol optical depth, single-scattering albedo and asymmetry parameter. If asymmetry parameter is not available, its climatological value (0.7) is applied.

\section{Results and Discussion}

Monthly means of solar surface irradiance are calculated with the different aerosol climatologies and subsequently compared to ground measurements of the Baseline Radiation Network (BSRN) [37] for all sky conditions. The comparison is performed for the period 2006-2009. The BSRN stations used for the validation are listed in Table 1. Only those stations were used that cover at least a period of 1 year.

Table 1. List of BSRN stations used.

\begin{tabular}{ccccccc}
\hline Station & Country & Code & $\begin{array}{c}\text { Latitude } \\
(\boldsymbol{D} \boldsymbol{e g} \boldsymbol{N})\end{array}$ & $\begin{array}{c}\text { Longitude } \\
(\boldsymbol{D} \boldsymbol{e} \boldsymbol{g} \boldsymbol{E})\end{array}$ & $\begin{array}{c}\text { Elevation } \\
(\boldsymbol{m})\end{array}$ & Number of Months \\
\hline Palaiseau & France & pal & 48.73 & 2.21 & 156 & 16 \\
Lerwick & UK & ler & 60.13 & -1.18 & 84 & 13 \\
Lindenberg & Germany & lin & 52.21 & 14.12 & 125 & 12 \\
Carpentras & France & car & 44.05 & 5.03 & 100 & 48 \\
Payerne & Switzerland & pay & 46.81 & 6.94 & 491 & 48 \\
Sede Boger & Israel & sbo & 30.9 & 34.78 & 500 & 48 \\
Tamanrasset & Algeria & tam & 22.78 & 5.51 & 1385 & 48 \\
Toravere & Estonia & tor & 58.25 & 26.46 & 70 & 48 \\
Cabauw & Netherlands & cab & 51.97 & 4.93 & 0 & 48 \\
\hline
\end{tabular}

The selected 9 stations are located on the northern hemisphere but cover several climatic regions (desert, maritime, continental). However, please note that the limited number of stations does not allow to draw final conclusions on the global performance of the climatologies.

The stations Toravere, Lerwick, Cabauw, Lindenberg and Payerne are on average characterized by moderate aerosol load, but relatively high frequency of clouds. Whereas the stations Tamanraset and Sede Boger are characterised by low frequency of clouds and higher aerosol loads might be expected. Both stations are affected by desert storms, hence a higher variability of the aerosol optical depth might be assumed. Indeed, Gueymard [14] showed that Sede Boger has a higher variability in aerosol optical depth than sites in Central Europe.

For the comparison only the aerosol input is changed, all other input variables remained unchanged. This enables the detection of the aerosol climatology resulting in solar surface irradiance with the lowest error. As main error measure the Mean Absolute Bias is used. It is defined by Equation (4). 


$$
M A B=\sum_{i}\left|R A D m m_{s a t}^{i}-R A D m m_{g b m}^{i}\right|
$$

Further the bias is used, defined as:

$$
\text { Bias }=\sum_{i} R A D m m_{\text {sat }}^{i}-R A D m m_{g b m}^{i}
$$

RADmm is the monthly mean of radiation for satellite (sat) and ground measurements (gbm), respectively. The absolute bias is preferred as, in contrast to RMSE, it is a linear quantity and avoids bias cancellation of errors across months or stations.

Figure 2 (absolute units) and Figure 3 (relative units) as well as Table 2 show the results of the evaluation.

Table 2. Mean Absolute Bias (MAB) over all stations for global irradiance $\mathrm{G}$ and direct (beam) irradiance $\mathrm{B}$ in absolute units $W / \mathrm{m}^{2}$ and relative units $\%$ MAB deviation relative to the mean. The last two lines provide the bias in $W / m^{2}$. The last column provides the results for the assumption of zero tropospheric aerosol content.

\begin{tabular}{cccccc}
\hline Variable & GADS/OPAC & MAC-v1 & Kinne & MACC & Zero Trop. Aerosol \\
\hline MAB G in $W / m^{2}$ & 10.0 & 9.4 & 10.4 & 6.8 & 8.0 \\
in $\%$ & 5.4 & 5.0 & 5.5 & 3.8 & 5.1 \\
MAB B in $W / m^{2}$ & 14.6 & 14.8 & 17.1 & 11.3 & 25.8 \\
in $\%$ & 12.8 & 12.7 & 14.9 & 9.9 & 23.9 \\
Bias G in $W / m^{2}$ & -7.4 & -7.0 & -8.4 & -4.0 & 5.4 \\
Bias B in $W / m^{2}$ & -10.5 & -11.7 & -14.7 & -7.6 & 24.6 \\
\hline
\end{tabular}

In general aerosols have a high scattering portion. The scattered light can contribute to global irradiance but is lost for the direct irradiance. This explains why direct irradiance exhibits a higher sensitivity to aerosols than global irradiance [38]. Hence, uncertainties in the AOD affects direct irradiance much more than global irradiance. This in turn explains that all climatologies shows higher errors for direct irradiance than for global irradiance.

MAC.v1, the sucessor of Kinne, performs slightly better than Kinne. However, the new MAC.v1 climatology is on the same level as the "old" GADS/OPAC climatology with its coarse spatial and temporal resolution. This is a remarkable result which might indicate the difficulty to gain a significant improvement in aerosol information for surface irradiance retrieval. At least for this comparison the higher spatial resolution provides no significant benefit. For global irradiance neither MAC-v1 nor Kinne nor GADS/OPAC perform better than the assumption of zero tropospeheric aerosols. This surprising result is further discussed in one of the following paragraphs. 
Figure 2. Mean Absolute Bias (mean absolute difference) of the global irradiance (MAB-G, top) and the direct irradiance (MAB-B, bottom) for the investigated aerosol climatologies evaluated at nine different Baseline Surface Radiation Network (BSRN) stations (colored bars). "meanmab" is the mean MAB over all nine stations. The effect of aerosols on direct irradiance is much more pronounced. As a result much higher errors are apparent for direct irradiance.
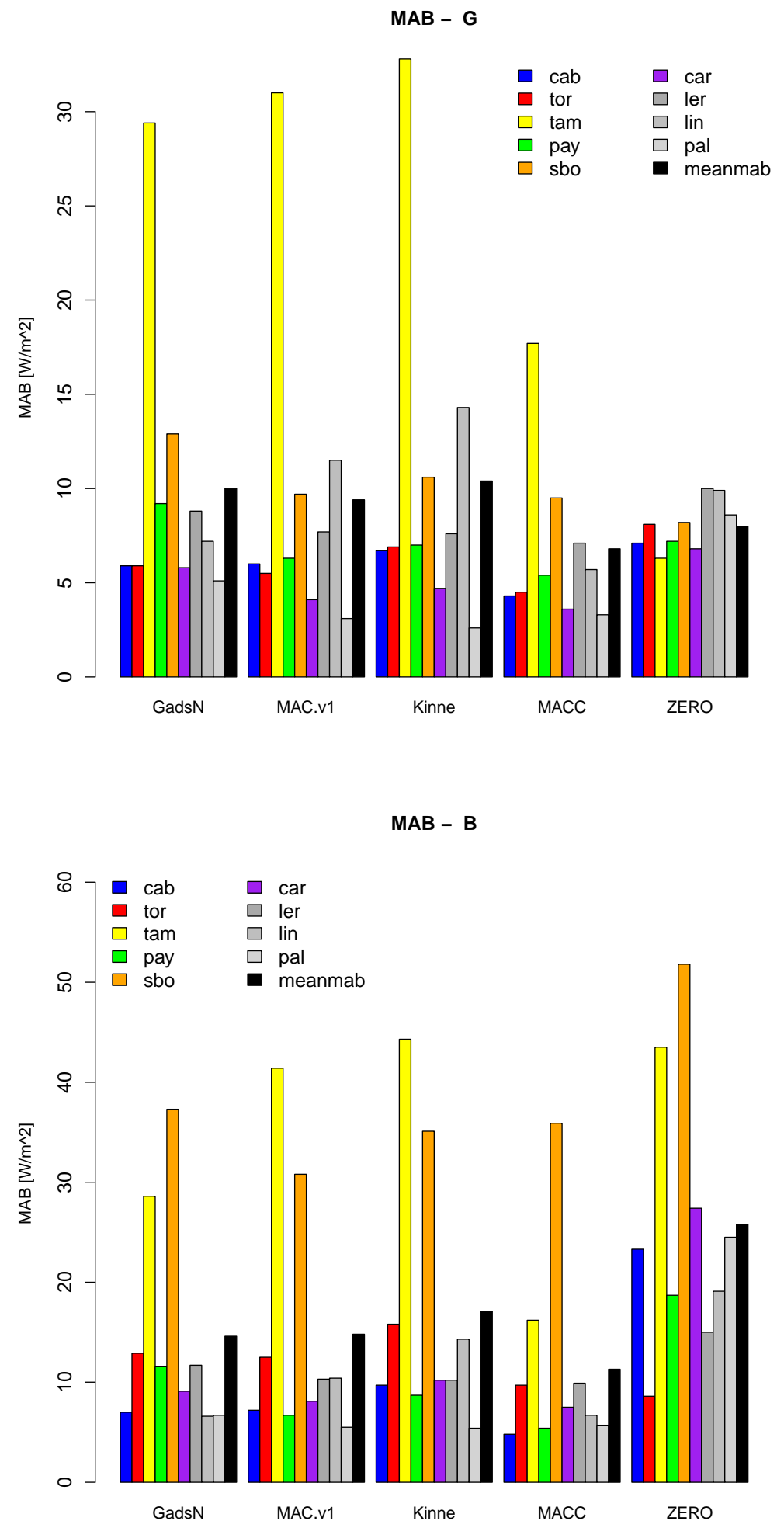
Figure 3. Relative deviation of the Mean Absolute Bias (mean absolute difference) for the global irradiance (MAB-G, top) and direct irradiance (MAB-B, bottom) from the mean radiation in percent. The large absolute difference of $\mathrm{MAB}$ at the station Tamanraset is much smaller in relative units, cause of the high mean of solar irradiance at this site. In contrast the relative deviation at the site Lerwick is relative high cause of the relative low mean solar irradiance.
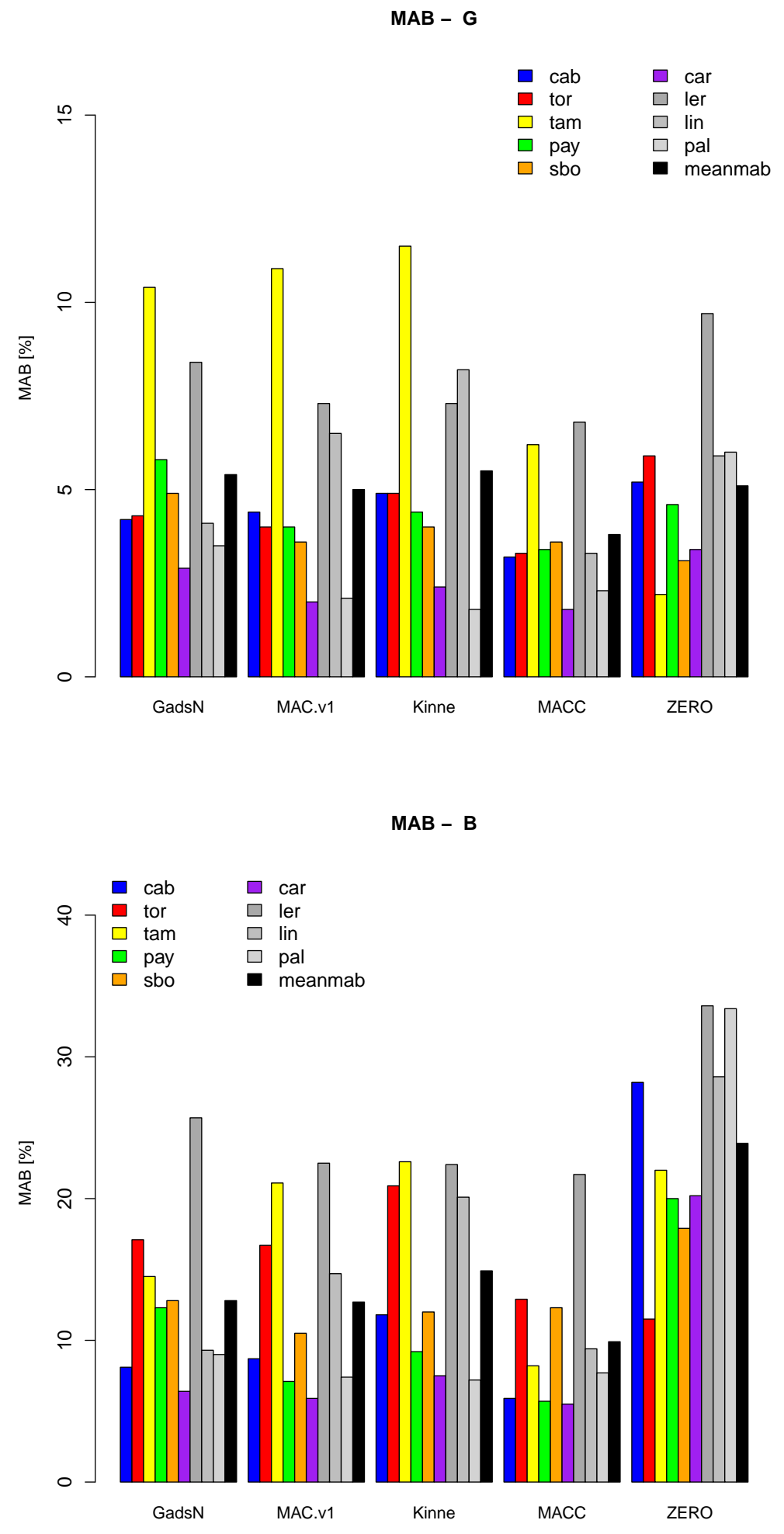
The use of the MACC aerosol climatology results by far to the highest accuracy, both for direct and global irradiance. The gain in accuracy is about $1 \%-2 \%$ for global irradiance and $3 \%-5 \%$ for direct irradiance compared to the other climatologies. Moreover, MACC is the only climatology that leads to a lower MAB than the zero (tropospheric) aerosol assumption for global irradiance. The use of MACC leads to remarkably good results with uncertainties close to the uncertainty of the ground measurements, with the exception of the stations Sede Boger and Tamanrasset where higher errors occur.

All climatologies show the largest errors (in absolute units) at these two stations (Sede Boqer and Tamanrasset). These sites are affected by desert aerosols and characterised by low frequency of cloud occurrence. This indicates that further improvements of the climatologies in and around the Sahara region might be needed.

However, in relative units the error at these stations is much less pronounced, because of the relatively high solar surface irradiance induced by high solar altitudes and low cloud amounts. Nevertheless, the higher MAB in $W / m^{2}$ of global irradiance using MAC.v1, Kinne and GADS/OPAC relative to the zero aerosol assumption is partly due to the large underestimation of global irradiance at these stations. MAC.v1, Kinne, and GADS/OPAC exhibit MAB values above $25 \mathrm{~W} / \mathrm{m}^{2}$, but the zero AOD assumption leads to a MAB of only $6.3 \mathrm{~W} / \mathrm{m}^{2}$ at Taramanset and $8.2 \mathrm{~W} / \mathrm{m}^{2}$ at Sede Boqer. This in turn leads to an overall comparable MAB for global irradiance and the surprisingly good performance of the zero aerosol assumption. All climatologies show a significantly lower MAB and Bias for direct irradiance compared to the zero aerosol assumption. This shows that the climatologies come with meaningful AOD information as the direct irradiance is only affected by AOD and not by the aerosol type or size. Global irradiance is less sensitive to AOD than direct irradiance and depends also on the aerosol type (composition) and size. Hence, the low performance for global irradiance relative to the zero aerosol assumption might be a hint for misleading single scattering albedo or asymetry parameter. The assumption of spherical aerosols might contribute significantly to misleading information in the Sahara region. Further, it might indicate that the absorption affect of the aerosols is overestimated. In any case the overall negative bias for direct and global irradiance indicates that at least for this type of retrieval methods the optical depth of the aerosol climatologies are too high. Yet, high aerosol loads (e.g., desert storms, biomass burning) might be considered as clouds by the applied retrieval method (Heliosat). This could contribute to the above mentioned finding and needs further investigation.

In order to get a first hint about the potential of inter-annually resolved data the year to year results are shown for the MACC climatology in Figure 4. It is remarkable that the error (MAB) of the climatologies (see Table 2) at the "clear sky" stations (Tamanrasset and Sede Boger) where higher aerosol variations are expected are significantly larger than the year to year variation. This indicates that an improvement of the climatology might be of higher priority, whereas the errors induced by the use of long term monthly means instead of annually resolved monthly means might be of lower priority.

For the European stations the error as well as the year to year variations are close to the uncertainty of the ground measurements for global irradiance.

This is at least also partly true for direct irradiance. Within this scope, it has to be considered that the uncertainty of ground measurements is higher for direct irradiance and that direct irradiance is more sensitive to uncertainties induced by clouds. Hence, based on our results, it is difficult to motivate the benefit of annually resolved aerosol data for regions such as Central and Northern Europe, which 
are characterized by relative low aerosol load but high frequency of clouds. In these regions clouds usually dominate the variation of radiation [38]. However, with regard to direct normal irradiance Gueymard [14] showed that regions with very high aerosol variations and very high aerosol sensitivity exists. It is to be expected that in those regions accurate inter-annual as well as daily aerosol information is of great importance for direct irradiance. Further, Nikitidou et al. [39] showed that the effect of variations in aerosols on DNI (e.g., induced by desert storms) could be rather large in Europe under clear skies. Such effects are not considered by climatologies, which is a serious drawback. On the other hand, high aerosol loads (desert storms, biomass burning) might be considered as clouds by the applied method. As mentioned above, this needs further investigation. In this context it is important to note that our results are restricted by the small number of available BSRN stations that cover the complete 4-year period, in particular with regard to DNI and direct irradiance.

Figure 4. Mean Absolute Bias (mean absolute difference) using MACC for different years (colored bars) at six Baseline Surface Radiation Network (BSRN) stations for global irradiance $(G$, left) and direct irradiance $(B$, right).
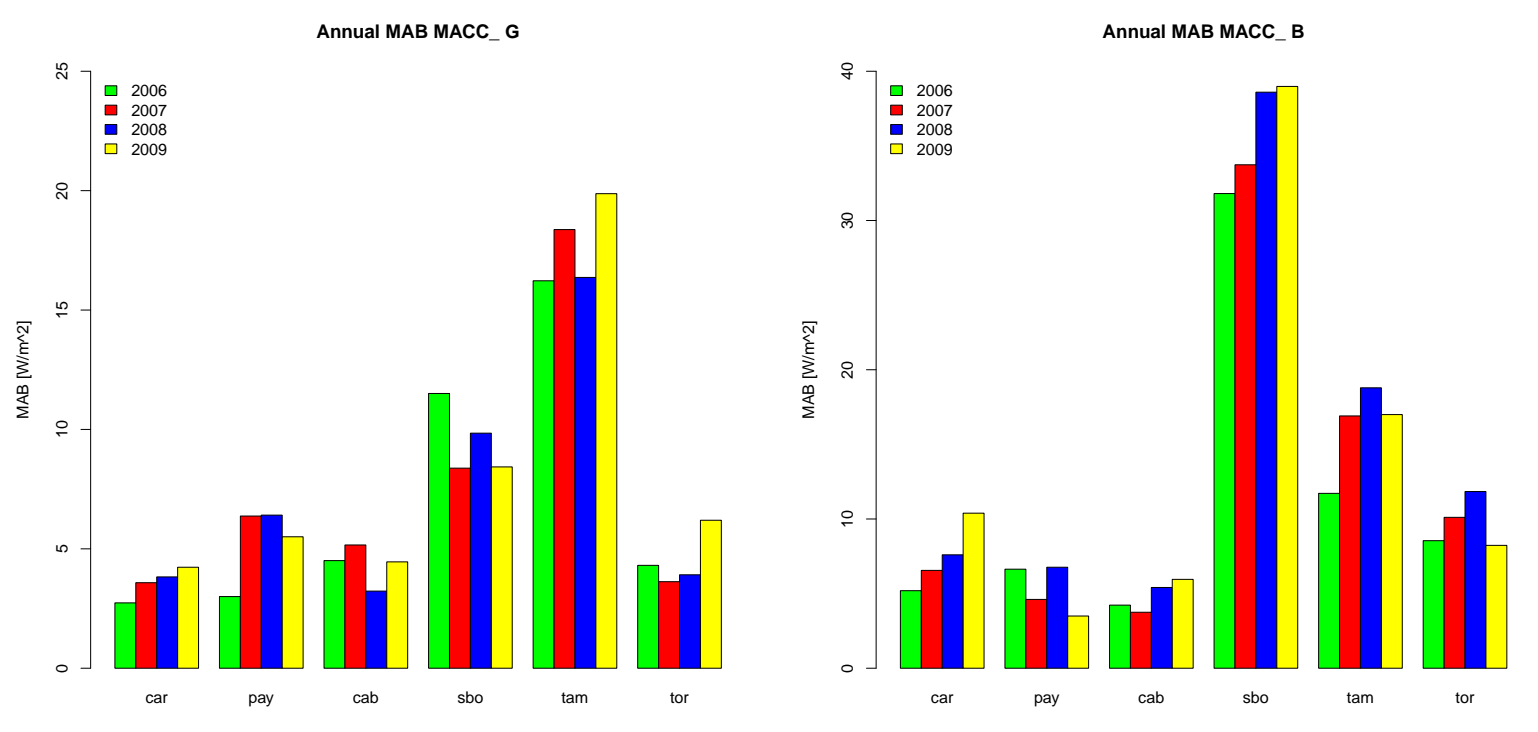

\section{Conclusions}

The sensitivity analysis of estimated solar surface irradiance (both direct and global) to aerosol climatology provided by four sources (MACC, GADS/OPAC, MAC-v1 and "Kinne") has been performed. The analysis involves the SPECMAGIG method [22] and data collected at nine BSRN ground-based stations. The collected data represent a 4-year period (2006-2009) and different observational conditions (desert, maritime, continental). It has been demonstrated that the MACC aerosol climatology, in comparison with those from other sources, offered better agreement between the calculated and measured values of the global irradiance and its direct component. The corresponding mean absolute bias was $6.8 \mathrm{~W} / \mathrm{m}^{2}$ and $11.3 \mathrm{~W} / \mathrm{m}^{2}$ for the global and direct irradiance, respectively.

Further, hints have been found that for global irradiance the improvement of the climatology might be of first priority, whereas the errors induced by the use of long term monthly means instead of annually resolved monthly means might be of lower priority. Also for direct irradiance the inter-annual variations are relatively small compared to the overall errors. However, our study is limited by the small number of 
sites available, which makes it impossible to draw final conclusions. Recent studies [14,39] have shown that higher temporal resolution is very important for direct irradiance in many regions of the world. Variations in AOD affect direct irradiance much more than global irradiance. However, the authors believe that issues regarding development of aerosol data sets with required quality and spatial coverage remain unresolved.

For climate data records homogeneity is an important issue. Given the high accuracy achieved with MACC and the need for homogeneity, the use of a climatology like MACC is expected to be appropriate for the retrieval of a climate data record of global and direct irradiance. Recent validation results performed within the generation of the SARAH data set confirm this assumption. However, it has to be expected that the use of aerosol climatologies contributes significantly to higher errors of direct irradiance retrieval.

\section{Acknowledgments}

This work is partly funded by the European Organisation for the Exploitation of Meteorological Satellites (EUMETSAT) within the framework of the Satellite Application Facillity. We thank the European tax payers, as the funding is originally given by them.

\section{Author Contributions}

Christine Träer-Chatterjee performed the evaluation of the aerosol climatologies and contributes to the writing of the manuscript. Richard Müller mentored the evaluation and wrote most parts of the manuscript. Both authors worked on the interpretation and disccussion of the results.

\section{Conflicts of Interest}

The authors declare no conflict of interest.

\section{References}

1. Dobler, A.; Müller, R.; Ahrens, B. Development and evaluation of a simple method to estimate evaporation from satellite data. Meteorol. Z. 2011, 20, 615-623.

2. Babst, F.; Mueller, R.; Hollmann, R. Verification of NCEP reanalysis shortwave radiation with mesoscale remote sensing data. Geosci. Remote Sens. Lett. 2008, 5, 34-38.

3. Träger-Chatterjee, C.; Mueller, R.W.; Trentmann, J.; Bendix, J. Evaluation of ERA-40 and ERA-interim re-analysis incoming surface shortwave radiation datasets with mesoscale remote sensing data. Meteorol. Z. 2010, 19, 631-640.

4. Hammer, A.; Heinemann, D.; Hoyer, C.; Kuhlemann, R.; Lorenz, E.; Mueller, R.; Beyer, H. Solar energy assessment using remote sensing technologies. Remote Sens. Environ. 2003, 86, 423-432.

5. Journée, M.; Müller, R.; Bertrand, C. Solar resource assessment in the Bebelux by merging Meteosat-derived climat data and ground measurements. Sol. Energy 2012, 86, 3561-3574.

6. Möser, W.; Raschke, E. Incident solar radiation over Europe estimated from METEOSAT data. J. Clim. Appl. Meteor. 1984, 23, 166-170. 
7. Cano, D.; Monget, J.; Albuisson, M.; Guillard, H.; Regas, N.; Wald, L. A method for the determination of the global solar radiation from meteorological satellite data. Sol. Energy 1986, 37, 31-39.

8. Bishop, J.; Rossow, W. Spatial and temporal variability of global surface solar irradiance. J. Geophys. Res. 1991, 96, 839-858.

9. Pinker, R.; Laszlo, I. Modelling surface solar irradiance for satellite applications on a global scale. J. Appl. Meteor. 1992, 31, 166-170.

10. Darnell, W.; Staylor, W.; Gupta, S.; Ritchey, N.; Wilber, A. Seasonal variation of surface radiation budget derived from ISCCP-C1 data. J. Geophys. Res. 1992, 97, 15741-15760.

11. Rigolier, M.; Levefre, M.; Wald, L. The method Heliosat-2 for deriving shortwave solar radiation from satellite images. Sol. Energy 2004, 77, 159-169.

12. Mueller, R.; Matsoukas, C.; Gratzki, A.; Hollmann, R.; Behr, H. The CM-SAF operational scheme for the satellite based retrieval of solar surface irradiance-a LUT based eigenvector hybrid approach. Remote Sens. Environ. 2009, 113, 1012-1022.

13. Kinne, S.; Schulz, M.; Textor, C.; Guibert, S.; Balkanski, Y.; Bauer, S.E.; Berntsen, T.; Berglen, T.F.; Boucher, O.; Chin, M.; et al. An AeroCom initial assessment-optical properties in aerosol component modules of global models. Atmos. Chem. Phys. 2006, 6, 1815-1834.

14. Gueymard, C.A. Temporal variability in direct and global irradiance at various time scales as affected by aerosols. Sol. Energy 2012, 86, $3544-3553$.

15. Geiger, B.; Meurey, C.; Lajas, D.; Franchisteguy, L.; Carrer, D.; Roujean, J. Near real-time provision of downwelling shortwave radiation estimates derived from satellite observations. Meteorol. Appl. 2008, 15, 411-420.

16. Ineichen, P.; Barroso, C.; Geiger, B.; Hollmann, R.; Mueller, R. Satellite application facilities irradiance products: Hourly time step comparison and validation. Int. J. Remote Sens. 2009, 30, 5549-5571.

17. Fontoynont, M.; Dumortier, D.; Heinemann, D.; Hammer, A.; Olseth, J.; Skartveit, A.; Ineichen, P.; Reise, C.; Page, J.; Roche, L.; et al. Satellight: An European Programme Dedicated to Serving Daylight Data Computed from Meteosat Images. Available online: http://www.satellight.com/indexgT.htm (accessed on 25 November 2014).

18. Wald, L.; Albuisson, M.; Best, C.; Delamare, C.; Dumortier, D.; Gaboardi, E.; Hammer, A.; Heinemann, D.; Kift, R.; Kunz, S.; et al. SoDa: A project for the integration and exploitation of networked solar radiation databases. In Environmental Communication in the Information Society; Pillmann, W., Tochtermann, K., Eds.; Number Part 2; International Society for Environmental Protection: Vienna, Austria, 2002; pp. 713-720.

19. Huld, T.; Müller, R.; Gambardella, A. A new solar radiation database for estimating PV performance in Europe and Africa. Sol. Energy 2012, 86, 1803-1815.

20. The Climate Monitoring Satellite Application Facillity (CM-SAF). Available online: www.cmsaf.eu (accessed on 28 November 2014).

21. Mueller, R.; Trentmann, J.; Träger-Chatterjee, C.; Posselt, R.; Stöckli, R. The role of the effective cloud Albedo for climate monitoring and analysis. Remote Sens. 2011, 3, 2305-2320. 
22. Mueller, R.; Behrendt, T.; Hammer, A.; Kemper, A. A new algorithm for the satellite-based retrieval of solar surface irradiance in spectral bands. Remote Sens. 2012, 4, 622-647.

23. Mayer, B.; Kylling, A. Technical note: The libRadtran software package for radiative transfer calculations-Description and examples of use. Atmos. Chem. Phys. 2005, 5, 1855-1877.

24. Shettle, P.; Fenn, R.W. Models of the atmospheric aerosols and their optical properties. AGARD Conference Proceedings No. 183, Optical propagation in the atmosphere, Symposium, Lyngby, Oct. 1975, 1976.

25. Shetlle, E. Models of aerosols, clouds and precipitation for atmospheric propagation studies. In Proceedings of AGARD Conference No. 454, Atmospheric Propagation in the UV, Visible, IR and MM-region and Related System Aspects, Copenhagen, Denmark, 9-13 October 1989.

26. Posselt, R.; Mueller, R.; Stöckli, R.; Trentmann, J. Spatial and temporal homogeneity of solar surface irradiance across satellite generations. Remote Sens. 2011, 3, 1029-1046.

27. Mueller, R.; Dagestad, K.; Ineichen, P.; Schroedter-Homscheidt, M.; Cros, S.; Dumortier, D.; Kuhlemann, R.; Olseth, J.; Piernavieja, G.; Resie, C.; et al. Rethinking satellite based solar irradiance modelling. The SOLIS clear-sky module. Remote Sens. Environ. 2004, 91, 160-174.

28. Holben, B.N.; Eck, T.F.; Slutsker, I.; Tanré, D.; Buis, J.P.; Setzer, A.; Vermote, E.; Reagan, J.A.; Kaufman, Y.J.; Nakajima, T.; et al. AERONET_A federated instrument network and data archive for aerosol characterization. Remote Sens. Environ. 1998, 66, 1-16.

29. Kinne, S.; O’ Donnel, D.; Stier, P.; Kloster, S.; Zhang, K.; Schmidt, H.; Rast, S.; Giorgetta, M.; Eck, T.F.; Stevens, B. MAC-v1: A new global aerosol climatology for climate studies. J. Adv. Model. Earth Syst. 2013, 5, 707-740.

30. FTP Server: The HACv1 aerosol data is available at the ftp server ftp-projects.zmaw.de in the directory aerocomclimatologyHACv1_2013.

31. Hess, M.; Koepke, P.; Schult, I. Optical properties of aerosols and clouds: The software package OPAC. Bull. Amer. Meteor. Soc. 1998, 79, 831-844.

32. Kalnay, E.; Kanamitsu, M.; Kistler, R.; Collins, W.; Deaven, D.; Gandin, L.; Iredell, M.; Saha, S.; White, G.; Woollen, J.; etal. The NCEP/NCAR 40-year reanalysis project. Bull. Am. Meteorol. Soc. 1996, 77, 437-471.

33. Inness, A.; Baier, F.; Benedetti, A.; Bouarar, I.; Chabrillat, S.; Clark, H.; Clerbaux, C.; Coheur, P.; Engelen, R.; Errera, Q.; etal. The MACC reanalysis: An 8 year data set of atmospheric composition. Atmos. Chem. Phys. 2013, 13, 4073-4109.

34. Morcrette, J.J.; Boucher, O.; Jones, L.; Salmond, D.; Bechtold, P.; Beljaars, A.; Benedetti, A.; Bonet, A.; Kaiser, J.W.; Razinger, M.; et al. Aerosol analysis and forecast in the European centre for medium-range weather forecasts integrated forecast system: Forward modeling. J. Geophys. Res. 2009, 114, doi:10.1029/2008JD011235.

35. Benedetti, A.; Morcrette, J.J.; Boucher, O.; Dethof, A.; Engelen, R.; Fisher, M.; Flentje, H.; Huneeus, N.; Jones, L.; Kaiser, J.; et al. Aerosol analysis and forecast in the European centre for medium-range weather forecasts integrated forecast system: 2. Data assimilation. J. Geophys. Res. 2009, 114, doi:10.1029/2008JD01111.

36. Bellouin, N.; Quaas, J.; Morcrette, J.J.; Boucher, O. Estimates of aerosol radiative forcing from the MACC re-analysis. Atmos. Chem. Phys. 2013, 13, 2045-2062. 
37. Ohmura, A.; Dutton, E.; Forgan, B.; Fröhlich, C.; Hegner, H.; Heimo, A.; König-Langlo, G.; Mc Arthur, B.; Müller, G.; Philipopon, R.; etal. Baseline Surface Radiation Network (BSRN/WCRP): New precision radiometry for climate research. Bull. Am. Met. Soc. 1998, 79, 2115-2136.

38. Müller, R. Solar irradiance, global distribution. In Encyclopedia of Sustainable Science and Technology; Meyers, R.A., Ed.; Springer: Berlin, Germany, 2012; Volume 1, pp. 9699-9729.

39. Nikitidou, E.; Kazantzidis, A.; Salamalikis, V. The aerosol effect on direct normal irradiance in Europe under clear skies. Renew. Energ. 2014, 68, 475-484.

(c) 2014 by the authors; licensee MDPI, Basel, Switzerland. This article is an open access article distributed under the terms and conditions of the Creative Commons Attribution license (http://creativecommons.org/licenses/by/4.0/). 